\title{
LOS DESPAIGNE EN SAINT-DOMINGUE Y CUBA: NARRATIVA MICROHISTÓRICA DE UNA EXPERIENCIA ATLÁNTICA*
}

POR

MARIAL IGLESIAS UTSET

Una familia de plantadores franceses en Jérémie, en el sur de Saint-Domingue, cuyo mundo colapsa a consecuencia de la revolución de Haití, reproduce nuevamente en las serranías de El Cobre, en Santiago de Cuba, la economía (material y moral) de la plantación cafetalera. Medio siglo más tarde, la irrupción de las guerras de independencia de España emancipa a los numerosos esclavos de la plantación, cuya inclusión ciudadana, ya en la república cubana en el siglo XX, se pone a prueba en 1912, cuando el alzamiento de los miembros del Partido de los Independientes de Color reactualiza traumáticamente la memoria de la revolución de Haití en Cuba.

Palabras Clave: Haití, Cuba, esclavitud, emancipación, raza.

UNA «RELIQUIA» EN EL MUSEO NACIONAL

En 1913 alguien donó al entonces recién inaugurado Museo Nacional de Cuba un sobre que contenía un pedazo de papel: una proclama, arrugada y rota, con unas manchas oscuras que resultaron ser trazas de sangre. El volante, una hoja suelta impresa en Santiago de Cuba, reproducía una entrevista de Evaristo Estenoz, el líder nacional de un partido político fundado en la Habana en 1908 con el propósito de representar los intereses de los sectores negros de la población cubana. La proclama reafirmaba, entre otros tópicos, la decisión

* El presente texto ha sido preparado en el marco del proyecto HAR2009-07037/HIST del Ministerio de Ciencia e Innovación durante una estancia en la Universitat Jaume I (INV-2010-29). 
de los integrantes del partido «a ejercitar nuestros derechos de cubanos en lo adelante, exigir la igualdad y pedir constantes reformas hasta hacer más perfecta la democracia cubana y más tangible la libertad».

Etiquetada con el número $1443 \mathrm{y}$ archivada en los fondos del museo en compañía de un sinnúmero de artefactos y documentos, en su mayoría «patrióticos», la hoja perdió su condición de objeto itinerante para terminar convertida en artículo de colección ${ }^{1}$. Pero antes, había estado en el bolsillo de Justo Despaigne, un hombre negro que fue asesinado en el cafetal Kentucky el 12 de junio de 1912 por las tropas del ejército de la república enviadas a reprimir la protesta armada con la cual el Partido de los Independientes de Color intentaba reivindicar su derecho a la existencia como institución política $^{2}$.

Seguramente algún soldado de los que participaron en la acción militar retiró la proclama manchada de sangre del cadáver como prueba incriminatoria, o quizás a título de trofeo o souvenir. Algún tiempo más tarde, la hoja fue enviada al museo habanero como «Reliquia de la Revolución Racista», según se consignó en el sobre que la contenía. Se desconoce si alguna vez fue puesta en exhibición aunque es bastante improbable, ya que muy rápidamente una capa de silencio sepultó la memoria del acontecimiento que marcara, 26 años después de la emancipación de la esclavitud, el punto más alto de la violencia racista en la Cuba republicana. Sin embargo, casi un siglo después, la maltrecha hoja suelta, luego de ser vehículo de propaganda política, trofeo de guerra y, más tarde, pieza de museo, devendría esta vez «documento», convertida en una suerte de pieza testimonial cuya interpretación sirve de leitmotiv en esta investigación.

Cuando murió con la proclama doblada en su bolsillo, en los terrenos de un cafetal en las serranías del oriente de Cuba, Justo Despaigne tenía unos 50 años. Hijo y nieto de esclavos, había nacido también en un cafetal, en El Cobre, donde sus padres y antes sus abuelos habían pasado la vida cultivando café para una familia de plantadores criollos procedentes de Saint-Domingue, cuyo fundador, Jean Despaigne, arribó a Santiago de Cuba a inicios del siglo XIX huyendo de la revolución de Haití. Esta pesquisa intenta reconstruir la cadena de acontecimientos que enlaza el éxodo angustioso de la familia Despaigne de Jérémie, en el sur de Saint-Domingue, en 1803, con la muerte violenta en el oriente de Cuba del ex esclavo y veterano negro Justo Despaigne, en 1912.

1 Archivo Nacional de Cuba, La Habana (ANC), Museo Nacional, caja 7, número 8.

2 La Discusión, La Habana, 13 de junio de 1912. 
Así, la saga de los Despaigne en Cuba es la historia de tres generaciones de personas, amos y esclavos, blancos y negros, descendientes de europeos y gente con raíces en África, con destinos inseparablemente unidos a lo largo de casi un siglo: atados a una extensión de tierra, varias caballerías plantada de cafetos en la serranía del Cobre cuya explotación se tradujo en vidas de bonanza para los propietarios blancos y violencia física y deshumanización para sus víctimas.

Sin embargo, esta historia menor de una sola familia y de sus varios centenares de esclavos, aparentemente constreñida a un ámbito sumamente local, los confines de unos cafetales en un enclave rural en el extremo este de la isla, es al mismo tiempo una historia atlántica, notablemente trasnacional ${ }^{3}$.

\section{«UNIDOS AL SUELO A CAUSA DE SU DESTINO»: ATADURAS LOCALES Y VÍNCULOS TRASATLÁNTICOS}

Jean Despaigne, y Pierre, su hermano, nacidos en Cap François, provenían, como muchos colonos de Saint-Domingue, de una antigua familia bordelesa. La vida de los hermanos Jean y Pierre Despaigne había sido radicalmente afectada por la conmoción revolucionaria, que los arrojó, después del incendio de su ciudad natal en 1793, primeramente al sur, a la zona ocupada por los ingleses, y después a las costas del este de Cuba, ya en el capítulo postrero de la revolución. Sin embargo, el origen del capital que le permitió a Jean Despaigne volver establecerse como plantador de café, comprando tierras y esclavos en el este de Cuba, procedía del patrimonio de su suegra, que lo acompañó, junto a su esposa y su pequeños hijos, en la huida desde Jérémie, apenas unos meses antes de la proclamación por Dessalines de la república de Haití. Antoinette Kanon era a su vez hija de Jacques Kanon, un personaje con una vida atlántica ejemplar para el siglo XVIII francés.

Nacido en 1726, en Blaye, una pequeña ciudad portuaria cercana a Burdeos en la entrada del río Gironda, Kanon era hijo y nieto de navegantes vinculados al comercio colonial. En 1738 a la temprana edad de 12 años, Jacques Kanon hizo su primer viaje a Saint-Domingue, fungiendo como grumete en el barco de su propio padre. Después de atravesar el Atlántico durante años como oficial de la marina francesa y también como corsario Kanon decidió emprender un negocio aún más lucrativo: en 1763 se inició como traficante negrero. Tres viajes sucesivos a las costas de África lo convirtieron en un hombre aco-

3 Sobre el juego de escalas entre la metodología de la microhistoria y la historia atlántica, véase: Scott, 105 (Washington, 2000): 472-479. Putnam, $39 / 3$ (Fairfax, VA, 2006): 615-630. 
modado: en 1765 fue elegido «bourgeois de Bordeaux», y ese mismo año, iniciado en la logia masónica bordelesa l'Amitié. En 1770, probablemente alentado por el impetuoso boom de la economía colonial, Kanon resolvió darle un giro decisivo a su vida. A sus 44 años, tomó la arriesgada decisión de reinvertir en Saint-Domingue el capital acumulado con negocios de vinicultura en su natal Burdeos y el tráfico de esclavos. Entre 1771 y 1788 Jacques Kanon se hizo de una propiedad azucarera en la ribera del río Guinodée cercano a Jérémie, y años más tarde fundó otra plantación en la Voldrogue, en conjunto con su yerno, Jean Chalmette, dueño a su vez de tierras en la Grande-Rivière. Los negocios prosperaron y hacia 1790 Kanon poseía, además de las plantaciones de azúcar, dos comercios, una casa en la ciudad y otros terrenos en el área de Jérémie. En 1800, en pleno apogeo de la revolución, moriría en Burdeos, probablemente arrepentido de su aventura colonial como plantador ${ }^{4}$.

Pero no sólo los propietarios blancos europeos tenían un pasado trasatlántico. Hacia la tercera década del siglo XIX, al menos la mitad de los esclavos de las plantaciones de los Despaigne habían nacido en África y cruzado el Atlántico, sobreviviendo al angustioso viaje que los historiadores han dado en llamar la «travesía intermedia». A la muerte de Jean Despaigne, en 1849, el avalúo de sus bienes arroja luz sobre la procedencia étnica de sus esclavos: de los 63 esclavos de sexo masculino del cafetal La Lisse, 32 eran africanos de origen, una mayoría «congos», denominación étnica que designa de manera general una cultura de origen bantú y una procedencia geográfica localizada en el estuario del río Congo, pero también «ibó» (igbo) y «bibí» (ibibio), dos de las etnias del hinterland de la ensenada de Biafra, en delta del Níger ${ }^{5}$.

De este modo, aún dentro de la reducida demarcación de La Lisse, coexistían varias leguas: el francés, el idioma de los amos blancos europeos, y quizás también el castellano, necesario para la comunicación externa; las originarias de África, habladas por los esclavos de la plantación, probablemente alguna

4 Sobre la vida de Jacques Kanon, véase Deschênes, 2010a; 2010b. Los detalles sobre los viajes de Kanon como traficante de esclavos pueden consultarse en el sitio web Transatlantic SlaveTrade Database, viajes 31526, 31542, 31571. Sobre las propiedades de la famila Kanon-Despaigne en Jérémie: Notario Girard, 5-136. Notario: L'Epine, 6B-193, 6C-83, 6D-47, 6D-50. Notario Dobignies, 9-215. Notario: Layne, 8-130; 8-160, Jérémie Papers, Colecciones especiales, Biblioteca de la Universidad de la Florida, Gainesville.

5 Testamentaria de Juan Despaigne y su consorte Luisa Chalmette, ANC, Audiencia de Santiago de Cuba, leg. 171, núm. 3089. Juan Despaigne muere en 1847, pero los avalúos para iniciar el proceso de la herencia son realizados en 1849. Para una excelente síntesis de la historia, económica, política y cultural del comercio de esclavos trasatlántico véase: Klein, 2010. Para una visión general del proceso de la esclavitud y la emancipación en una dimensión comparativa véase: Engerman, 2007. 
lengua bantú como el kikongo, junto con el igbó y el ibibio o quizás el efik, y, finalmente, una lengua híbrida, el creole, que importado de Saint-Domingue, era usado en las plantaciones de café de los franceses como lengua franca en la vida de cada día. Esta extraordinaria polifonía lingüística en los límites de un solo cafetal permite inferir la compleja matriz del intenso proceso de reverberación cultural que caracterizó la experiencia de la esclavitud de plantación en el Caribe ${ }^{6}$.

Con independencia del origen atlántico de los protagonistas de la historia, sus vidas estaban además atadas a vínculos que iban mucho más allá de los lindes de los cafetales serranos o incluso de las mismas fronteras de la isla. A diferencia del ámbito limitado de la agricultura tradicional de subsistencia, circunscrita frecuentemente a condiciones locales, la relación entre amos y esclavos en una plantación comercial caribeña como la de los Despaigne estaba mediada por procesos de alcance global. Así, eventos gobernados por la «mano invisible» de la oferta y la demanda, para usar la metáfora de Adam Smith, o dictados por las lógicas de las políticas imperiales, ocurridos en puntos del mundo tan extraordinariamente distantes unos de otros como los puertos y urbes europeas o los poblados y factorías en África occidental, afectaban las dinámicas del comercio de esclavos o los precios de cotización del café. Y al hacerlo, incidían también en la vida de cada día de un cafetal del otro lado del Atlántico, en los confines rurales de una isla en el Caribe.

Con frecuencia, préstamos de dinero hechos en Burdeos, Nantes o París se cobraban en las serranías del oriente de Cuba con trabajo forzado de africanos o sus descendientes. La hipoteca sobre la propiedad del cafetal Estrella, en Brazo del Cauto, Cobre, fue contraída por Augusto Enrique Despaigne, hijo del primogénito de Juan Despaigne, Juan Numa Despaigne, para respaldar una deuda de 89.250 francos con un prestamista parisino. El documento, redactado en 1865 ante un notario en París según las normas y el estilo estándar del derecho contractual burgués, no tiene nada de notable excepto un añadido: el texto especifica que «la hipoteca se extenderá no tan sólo a los inmuebles, tierras, bosques, plantíos y habitaciones, sino también a todos los objetos y seres animados, que se consideran como unidos al suelo e inmuebles a causa de su destino, especialmente a los esclavos».

Al tiempo que Augusto Enrique Despaigne y su acreedor parisino son reconocidos en el contrato hipotecario como individuos con plenos derechos a disponer libremente de sus personas, acciones y posesiones, los esclavos, téc-

6 Sobre las lenguas africanas y el creole de Haití, Appiah y Gates (eds.), 2005, III: $510-512$ y 514 . 
nicamente «seres animados, que se consideran como unidos al suelo e inmuebles a causa de su destino», se listan solamente por los nombres de pila, enumerados justo al resto de las propiedades del cafetal. Así, eventos ocurridos a miles de millas de distancia, como las deudas contraídas por un señorito de la familia blanca en París repercuten al otro lado del Atlántico en forma de una hipoteca que pesa sobre las vidas de 82 personas, hombres, mujeres y niños de origen africano, esclavizados en las serranías del Cobre ${ }^{7}$.

\section{LA DOBLE MEMORIA DE HAITÍ}

Por último, las vidas de los Despaigne, blancos y negros, estaban atadas también a la memoria de un acontecimiento traumático, con una enorme trascendencia para el legado posterior de la esclavitud: la revolución de Haití. Una memoria omnipresente en una zona del este de Cuba que a inicios del siglo XIX acogió a 18.000 personas, entre blancos, mulatos y negros, testigos presenciales de la revolución. Numerosos colonos blancos y también gente «de color», libres y esclavos, se establecieron en la isla, sobre todo en su parte oriental, dejando una huella profunda y duradera en la idiosincrasia y la cultura de esas regiones, palpable hasta el día de hoy.

Pero como es sabido, el impacto más importante de la historia de Haití sobre Cuba no estuvo relacionado con la emigración directa, sino con el propósito, ejecutado con éxito arrollador por la elite criolla y la administración colonial, de suplantar en el mercado mundial a Saint-Domingue, antes de la insurrección la colonia de plantación más eficiente y rica del mundo. En breve, los esfuerzos conjuntos de propietarios, comerciantes, traficantes de esclavos y funcionarios coloniales convirtieron a Cuba en una enorme factoría, una sociedad fundada en el azúcar, la esclavitud y el colonialismo, siguiendo una estrategia económica calcada de la de Saint-Domingue.

En los años que van de 1774 a 1817, con la importación masiva de esclavos, la población negra de la Isla se cuadriplicó, sobrepasando por primera vez a la de personas blancas en la composición demográfica. Con la prosperidad fundada en el trabajo forzado de miles de africanos, se arraigó también el pavor paranoico a la repetición de lo ocurrido en la vecina colonia francesa. Atrapados entre las lógicas contrapuestas del miedo a la rebelión y la avaricia y el cálculo frío de las ganancias que la esclavitud proporcionaba, los propietarios cubanos se debatieron en una tensión que marcó la historia de todo el si-

7 Archivo Histórico Provincial de Santiago de Cuba, Santigo de Cuba (AHPSC), Protocolos Notariales, leg. 116, año 1866, folio 12. 
glo XIX cubano, retrasando por varias décadas la independencia de España y la abolición.

A pesar de que las autoridades coloniales en Cuba hicieron todo lo posible en la época por restringir la circulación de noticias o la entrada de esclavos contaminados por la experiencia y las ideas sediciosas de la revolución, pronto la simple mención del nombre de Haití remitiría a un conjunto de imágenes estereotipadas que pasaban de boca en boca, infundiendo temor o esperanza, según el oyente. Como ha subrayado Ada Ferrer, a través de la mención y la invocación constantes, Haití devino una sinécdoque que, al tiempo que evocaba violencia, exterminio o venganza, también aludía peligrosamente al lenguaje de la libertad y los derechos ciudadanos.

La existencia de la memoria del grand peur blanco está bien documentada: miles de textos de diferente índole, noticias de periódicos, órdenes y cédulas, informes públicos, correspondencia oficial y privada, que hablan compulsivamente del temor de la reproducción de otro «Haití» en Cuba, se acumulan por doquier en archivos y bibliotecas. No obstante, sólo se conservan evidencias fragmentarias y distorsionadas (sobre todo como testimonios indirectos dentro de la documentación legal que generaban los episodios de las sublevaciones, conspiraciones y otras formas de sedición) del modo en que los esclavos y sus descendientes, en una abrumadora mayoría personas analfabetas, interpretaron e hicieron suya, al incorporarla a sus propias reivindicaciones políticas, la memoria de lo ocurrido en Saint-Domingue ${ }^{8}$. El ejemplo de una revolución en la que las personas que ocupaban el orden más bajo de la sociedad, los esclavos, apropiándose de las consignas de liberté, égalité, fraternité y del discurso de los derechos naturales de la ilustración europea, lograron transformarse en ciudadanos, al menos en el plano formal, creando un estado soberano a partir de lo que fue una colonia de plantación esclavista, tuvo que haber despertado poderosas esperanzas entre los miles y miles de personas víctimas de la esclavitud en América9.

Esta investigación, al tiempo que intenta reconstruir, usando técnicas microhistóricas y prosopográficas, el hilo de las trayectorias vitales de varios de los numerosos esclavos de la familia Despaigne hasta los años posteriores de la emancipación, pretende también documentar la existencia de una memoria viva, local, del legado antiesclavista y antirracista de la revolución de Haití. De esta manera, estos son también los primeros resultados de un estudio mi-

8 Sobre el impacto de la revolución de Haití en Cuba: Ferrer, 2009, 2008, LXIII/ 229 (Madrid, 2003): 675-694; 2 (París, 2003): 335-336. Véase también González-Ripoll, Naranjo, Ferrer, García y Opatrný, 2004; Fischer, 2004.

9 Knight, 105/ 1 (Washington, 2000): 105. 
crohistórico de las complejas dinámicas de la post-emancipación y el acceso a la ciudadanía hasta la primera década del siglo XX. En 1912, cuando el alzamiento de los miembros del Partido de los Independientes de Color reactualizó la memoria de la revolución de Haití en Cuba, desatando una violenta oleada de racismo que puso a prueba la plena inclusión ciudadana de los cubanos negros, numerosos descendientes de esclavos de la familia francesa se encontraron nuevamente entre los encausados por rebelión.

\section{CruZando El PASO DE los Vientos: El ÉXOdo A SANTIAGO}

En lo que sería el último capítulo de la revolución en Saint-Domingue, hacia la primavera y el verano de 1803, a consecuencia del aumento de la escalada de violencia, miles de habitantes de la colonia francesa, blancos, mulatos y negros, junto a un sinnúmero de soldados del ejército francés en desbandada, huyeron de la devastación, arribando en todo tipo de embarcaciones a las costas del extremo oriental de Cuba. Los refugiados, unas 18.000 personas en total, al atravesar las escasas millas del Paso de los Vientos, el estrecho que separa el este de Cuba del suroeste de Haití, como ha subrayado recientemente Rebecca Scott, no sólo cambiaban de idioma y de jurisdicción, pasando del francés y el creole al castellano y de los dominios del imperio napoleónico a los del Rey de España, sino también de condición social ${ }^{10}$. Numerosos propietarios arruinados por la insurrección se vieron obligados a vivir de su propio trabajo personal en Santiago de Cuba, pero otros, entre los que parece haberse encontrado Jean Despaigne, se las arreglaron para preservar algún capital y arrastrar con ellos a varios de sus antiguos esclavos.

Las declaraciones de los capitanes de los barcos, que abarrotados de refugiados arribaban a la entrada del Morro de Santiago de Cuba, dan cuenta del alcance de la violencia de la revolución y del trauma experimentado por sus participantes: Jean Arnaud, el capitán la goleta Alegre, declaraba: «que haviendo (sic) sido la jurisdicción de Jeremías casi enteramente devastada por los negros rebeldes, todas las haciendas, dos de sus pueblos, Los Abricots y el Corail acometidos e incendiados y el de Jeremías amenazado de la misma suerte, sus habitantes se hallan obligados, para escapar al cuchillo de aquellos levantados, a buscar en las islas vecinas y amigas, la protección que ya no pueden encontrar en ningún puerto e aquella colonia» ${ }^{11}$. «Los negros rebeldes ha-

10 Scott, 52 (La Habana, 2009): 2.

11 Declaración de Jean (Juan) Arnaud, capitán la goleta francesa La Alegre, 11 de julio de 1803, ANC, Correspondencia de los Capitanes Generales, caja 63, núm. 7. 
bían quemado el día 19 los pueblos y labranzas que existían desde el Cavo (sic) de Tiburón hasta las inmediaciones de Jeremías, entregando al cuchillo todos los blancos sin excepción de sus mujeres y niños», testimoniaba a su arribo a Santiago Jean Audivert, el piloto de otra de las embarcaciones ${ }^{12}$. Sin embargo, para las personas negras que de algún modo terminaron siendo reesclavizadas en Cuba, la memoria de una revolución que los había emancipado de la servidumbre tenía que ser necesariamente diferente, sólo que apenas existe evidencia documental que testimonie sobre ella.

En medio de la crisis provocada por el arribo de miles de personas - refugiados blancos pero también varios miles de negros y mulatos - las autoridades santiagueras, por un lado, temían la amenaza de la propagación de las ideas subversivas y el «mal ejemplo» que encarnaban estos negros «franceses», testigos (y hasta quizás protagonistas) de la sublevación. Pero por el otro, necesitaban desesperadamente brazos en la cruzada emprendida para convertir a la Isla en un enorme sistema de plantación, capaz de ocupar el lugar que dejaban vacante las una vez muy eficientes colonias francesas. De modo que a pesar de las reiteradas instrucciones dadas por Salvador del Muro y Salazar, marqués de Someruelos y capitán general de la Isla, a Sebastián Kindelán, gobernador de Santiago, de impedir el desembarco de todo hombre negro mayor de 13 años en las costas de Cuba, hay numerosas evidencias de que miles de negros y mulatos encontraron refugio en la parte oriental del país. Aún cuando la historiografía tiende a representar esta primera inmigración como mayoritariamente blanca y «francesa», las cifras de un censo de 1808 contradicen este aserto: de las 7.449 personas procedentes de Saint-Domingue que permanecían en Santiago cinco años después del éxodo, el $72 \%$ eran de color, entre mulatos y negros libres y esclavos ${ }^{13}$.

Era cierto que por severas que fueran las medidas de control del gobierno español, la arribazón de una gran cantidad de embarcaciones hacía materialmente imposible la vigilancia de los cientos de kilómetros del litoral costero en la zona próxima a Saint-Domingue ${ }^{14}$. Pero más allá del temor a la extensión

12 Sebastián Kindelán al Marqués de Someruelos, Extracto de noticias ocurridas hasta el día de la fecha, Santiago de Cuba, 13 de julio 1803, Archivo General de Indias, Sevilla (AGI), Cuba, 1537A.

13 Pérez de la Riva, 1975: 372-374.

14 Ya desde 1802, cuando la emigración no era tan numerosa, Kindelán, en correspondencia con Someruelos, reconocía la imposibilidad de mantener el control: «Apliqué todos mis conatos a que se embarcaran en otras fragatas mucha parte de los franceses residentes en esta y con preferencia la gente de color de quién tanto había tenido que temer, y que cuantas remesas hacía de ellos en buques particulares, se frustraban volviendo a desembarcarse en las costas in- 
de insurrección, la oportunidad de hacerse de mano de obra sin pagar un centavo en tiempos en que el precio de los esclavos se había elevado considerablemente era demasiado tentadora. De esta forma, muchos de los refugiados negros y mulatos de Saint-Domingue, legalmente libres por el efecto del decreto de emancipación de la esclavitud de 1794, o quizás incluso hombres y mujeres nacidos libres en la colonia francesa, terminaron siendo reesclavizados en Cuba. Es difícil aventurar el destino posterior de los innumerables hombres negros que fueron separados y destinados al pontón del puerto con el propósito de su futura expulsión. Sin embargo, algunas líneas que sobrevivieron dentro de la correspondencia entre el gobernador Kindelán y el capitán general Someruelos sugieren que muchos quizás simplemente fueron vendidos como esclavos fuera de la isla, quizás en Costa Firme. Un grupo de más de 100 «negros franceses», «tanto libres como esclavos», especifica una carta, «de 13 años para arriva» (sic), le fueron entregados por Someruelos «en custodia» al comerciante Joseph Martí, quien los recluyó en una fragata que se hallaba a su cargo. Lo que el documento no explicita es que el catalán Joseph Martí era, en realidad, uno de los más connotados traficantes de esclavos de Santiago de Cuba $^{15}$.

No he logrado encontrar constancia documental del arribo exacto de Jean Despaigne, con su esposa, su suegra y sus dos pequeños hijos nacidos en Jérémie, a Santiago. Sin embargo, en septiembre de 1803 ya se encontraba en la ciudad. Junto con otros coterráneos, Despaigne se dirige «con la mayor veneración» al gobernador de la ciudad con el propósito de que los autorice a realizar la compra de la hacienda Santa Catalina, propiedad de Manuel Justíz, situada a 25 leguas de la ciudad. Según el texto de la misiva, los franceses se proponían fomentar haciendas cafetaleras, prometiendo «sujetarse al gobierno de España en todas sus leyes, preceptos y disposiciones y usos y costumbres ${ }^{16}$. Finalmente, la hacienda, con varias decenas de caballerías de tierra virgen en la zona de Guantánamo, fue vendida, y Despaigne, junto a otros colonos de Saint-Domingue, pasó a ser accionista de una sociedad comanditaria que intentaba promover la venta de lotes de tierra en Bur$\operatorname{deos}^{17}$.

mediatas, introduciéndose nuevamente en la ciudad». Santiago de Cuba, 30 de marzo de 1802. AGI, Cuba, 1536A.

15 El Marqués de Someruelos a Sebastián Kindelán, gobernador de Santiago de Cuba, La Habana, 2 de agosto de 1803, ANC, Correspondencia de los Capitanes Generales, caja 63, núm. 12. Portuondo, 2003: 73.

16 Santiago de Cuba, 30 de septiembre de 1803, AGI, Cuba, 1537B, núm. 981.

17 Portuondo, 1996: 112-113. 
Unos meses más tarde, a la altura de 1804, fecha de la proclamación oficial de la república de Haití por Dessalines, Jean Despaigne (Juan, a partir de ese momento) se había naturalizado español, jurando fidelidad a la monarquía borbónica, y, en asociación con Pierre (Pedro) Duverger, otro hacendado de Jeremías, estaba establecido como plantador, con una hacienda de café en la zona de Dos Bocas, en la que trabajaban 25 esclavos $^{18}$. Su hermano menor, Pierre Antoine Despaigne, quien había llegado de Jamaica, donde se había refugiado inicialmente, seguiría sus pasos, trabajando como mayoral del cafetal familiar. Evidentemente, no les faltaba el empuje y el espíritu empresarial que había caracterizado a la colonización británica y francesa en el Caribe y que los criollos cubanos estaban prestos a imitar de tan buen grado. A pocos años de su llegada eran propietarios de la hacienda cafetalera más productiva de la zona, y en 1809 habían duplicado la cantidad de esclavos del cafetal, con un total de 50 y 125.000 cafetos en producción ${ }^{19}$.

Sin embargo, el sino de la guerra perseguía a Juan Despaigne y a sus coterráneos de Saint-Domingue. Cuando apenas habían logrado trabajosamente establecerse, la invasión napoleónica a España en 1808 provocó una intensa reacción antifrancesa, que culminó en 1809 con el decreto de expulsión de los franceses de la Isla. A instancias de la capitanía general, el gobernador de Santiago, Sebastián Kindelán, dictó en abril de 1809 un bando que ordenaba la expulsión de los colonos de origen francés que no estuviesen naturalizados ${ }^{20}$. Nuevamente, varios miles de refugiados de Saint-Domingue tuvieron que malvender o abandonar sus propiedades y embarcarse a otros destinos, en su mayoría a Luisiana, en el sur de los Estados Unidos. Sin embargo, habiendo dejado en Cuba numerosos intereses económicos, familiares y amigos, los emigrados mantuvieron el contacto y una corriente de tráfico entre Nueva Orleáns y Santiago, de personas y mercancías, pero también de prácticas culturales (como la misma música) sostenida por varias décadas, dejó una huella duradera en la cultura y la historia de ambas urbes ${ }^{21}$.

Juan Despaigne, su mujer, su suegra y sus hijos pequeños lograron permanecer en la Isla. Él y su socio Pedro Duverger no sólo se habían naturalizado

18 Expediente instruido con el objeto de fomentar en esta Isla, el plantio, cultivo y beneficio del café, ANC, Junta de Fomento de la Isla de Cuba, legajo 92, núm. 3929. Portuondo, 1996: 114.

19 Estado de la habitaciones correspondientes a españoles y a extranjeros naturalizados, con expresión de su familia, esclavos y número de cafetos, ANC, Correspondencia de Capitanes Generales, legajo fuera de caja, núm. 11.

20 Portuondo, 1996: 117. Barcia, 2008.

21 Para un estudio de la emigración a Nueva Orleáns, véase: Lachance, $29 / 2$ (Lafayette, LA, 1988): 109-141. 
sino que habían probado su fidelidad como súbditos españoles realizado donativos - varios quintales de café de la cosecha de la finca - para la guerra contra Napoleón ${ }^{22}$. Su hermano Pierre tuvo peor suerte, a pesar de su solicitud para poder quedarse amparándose del estatus de naturalizado de su hermano Jean; su petición fue rechazada y tuvo que abandonar la isla para instalarse en Nueva Orleáns con su mujer y sus dos hijas menores ${ }^{23}$. Pese a todo, aunque sus bienes fueron embargados como los del resto de los franceses, los Despaigne lograron capear el temporal. En 1811, con José Bonaparte aún usurpando el trono en Madrid, una orden del Consejo de Regencia, en Cádiz, aprobó la devolución de las propiedades embargadas a los franceses naturalizados españoles, y en julio la medida tuvo efecto para un grupo de ellos, incluido Juan Despaigne. Apenas unos meses más tarde, en un censo de propiedades de los partidos de La Güira y Dos Bocas, Juan Despaigne y Pedro Duverger reaparecen nuevamente como propietarios en sociedad del cafetal La Vela. Según los datos del mismo padrón, en Tiguabos, otra zona cafetalera en ascenso, el 75\% de los esclavos estaban en manos de unos pocos propietarios franceses ${ }^{24}$.

\section{EL ALZA DE LOS PRECIOS Y EL FLORECIMIENTO DE LA PLANTACIÓN CAFETALERA: LAS SERRANÍAS DEL COBRE}

Después de la derrota napoleónica en 1814 y la restauración borbónica, el cambio del panorama político en Europa y el alza de los precios del café en el mercado mundial (los precios se quintuplican entre 1815 y 1820$)^{25}$, indujo hacia el final de la segunda década del siglo XIX a muchos emigrados de la

22 Relación de los donativos que se han ofrecido en manos del gobierno de Cuba para ocurrir a las atenciones actuales de España desde la publicación de la guerra contra Napoleón, Cuba, 19 de diciembre de 1808, ANC, Correspondencia de Capitanes generales, legajo 446, expediente 4.

23 Documentos que se refieren a las comunicaciones y acuerdos de las Juntas de Vigilancia de Santiago de Cuba durante el año 1809, ANC, Asuntos Políticos, legajo 210, núm.73. Debo la información sobre la estancia de Pierre Despaigne en Nueva Orleáns a la generosidad de Rebecca Scott, quien localizó en los archivos de la catedral de Saint Louis en Nueva Orleáns la inscripción de nacimiento de Pedro Ovidio Despaigne, hijo de Pierre Despaigne y Sophie Ducongé, donde además se consigna que su padre Pierre se desempeñaba como primer oficial de la guardia municipal de la ciudad. Inscripción de bautismo de Pedro Ovidio Despaigne, St. Louis Cathedral, New Orleans, Baptism, S FPC part 1, 1814-1815. Agradezco también a Emilie Gagnet Leumas, archivista de la Archidiócesis de Nueva Orleáns, la reproducción del documento original.

24 Cruz Ríos, 2006: 77. ANC, Gobierno general, legajo 392, núm. 18629.

25 Pérez de la Riva, 1975: 377; Portuondo, 1996: 129. 
Luisiana a regresar a Cuba e invertir en la industria del café. Otros hacendados franceses que habían permanecido en la isla, como Juan Despaigne, expandieron sus negocios, invirtiendo en nuevas tierras cafetaleras. Prudencio Casamayor, comerciante, armador de barcos (negreros y del corso francés) y también traficante de esclavos, quien en 1802 había comprado terrenos vírgenes a precios ínfimos en las serranías de Cobre, hizo dinero en un plazo muy breve, vendiéndolos en lotes de 10 caballerías a sus coterráneos ${ }^{26}$.

En menos de una década, la zona de la cuenca alta del río Cauto, que se extiende por unos doscientos kilómetros desde el firme de la Sierra Maestra hasta Dos Palmas, se fue poblando de cafetales y de caminos intramontanos que comunicaban las haciendas y facilitaban el acarreo del café hacia la ciudad. Una tradición oral describe al mismo Prudencio Casamayor en persona, teodolito en mano, trazando el entramado de senderos de la sierra cobrera. Sin embargo, más allá de que el emprendedor francés pudo haber hecho de ingeniero de caminos, con diseños y técnicas constructivas procedentes de Saint-Domingue, fueron manos de esclavos africanos las que trabajosamente desbrozaron el monte, acarrearon las piedras y construyeron los cientos de kilómetros de senderos que conservan hasta el día de hoy la reminiscencia del origen «francés»: son llamados por los pobladores locales «caminos de colín», es decir chemins de coline ${ }^{27}$.

Además de los importados a través de la Habana, varios miles de esclavos que proveían la mano de obra de los cafetales, fueron traídos al puerto de Santiago gracias a los esfuerzos conjuntos de empresarios locales con sociedades comanditas, como la del mismo Casamayor y el catalán Juan Sillegue; algunos ex corsarios de Saint-Domingue devenidos capitanes negreros; y varios armadores en Nantes y Burdeos que proveían las naves y el capital necesario para las expediciones. En los años que siguieron a la abolición de la trata en Francia, entre 1814 y 1831 , pese a las disposiciones del gobierno francés tratando de limitar el comercio de esclavos, barcos de esa bandera continuaron llegando al puerto de Santiago con cargazones de esclavos. Varias embarcaciones francesas registradas en Santiago simplemente cambiaron de bandera, y con los mismos capitanes, pero ahora en naves españolas, continuaron cruzando el Atlántico trayendo discretos alijos de esclavos de contrabando que introducían a menudo por pequeños puertos costeros orientales para evadir el control de las autoridades. De hecho, sólo en en la década que va entre 1810 y 1820 el

26 Pérez de la Riva, 1975: 377.

27 Ibidem: 378. 
número de esclavos de la jurisdicción de Santiago de Cuba pasó de 8.836 a 23.956, para un aumento de un $66 \%{ }^{28}$.

Pese a la apariencia virgen del entorno, los franceses que se asentaron en las serranías del Cobre beneficiándose del bajo precio de los terrenos montuosos, fundaban sus plantaciones en un área que tenía un pasado de varios siglos de luchas emancipatorias. Desde el siglo XVII los esclavos de las minas del Cobre aledañas habían combinado las demandas legales y las alianzas tácticas con la insurrección y el cimarronaje, hasta obtener en 1800 su manumisión definitiva ${ }^{29}$.

En el partido de Hongolosongo, un valle intramontano de la serranía del Cobre y un sitio cuya toponimia africana permite suponer que fue también alguna vez asentamiento de un palenque de esclavos, Juan Despaigne y su hijo Eduardo fundaron el primero de los varios cafetales que la familia poseyó en la zona y que estuvo en producción por bastante más de medio siglo. En 1828 La Lisse tenía plantados 1.300 pies de café, cultivados con el esfuerzo de 24 esclavos, entre hombres y mujeres ${ }^{30}$. Para esa fecha, un cuarto de siglo después del arribo a Cuba de la familia Despaigne, es poco probable que un número significativo de los esclavos de La Lisse tuviera alguna relación directa, como participante o testigo, con la experiencia revolucionaria de Haití. De hecho, la mayor parte de la dotación estaba compuesta de esclavos bozales, traídos directamente de África occidental. Pero, como era usual en las plantaciones de colonos franceses, en parte por tradición y en parte por tratar de aislarlos del entorno, los esclavos eran enseñados a hablar creole, usado como lengua franca en la comunicación diaria, $\mathrm{y}$, frecuentemente, recibían nombres y apelativos franceses en lugar de castellanos. De este modo, bastaba con que algún esclavo anciano comunicara oralmente, en la lengua de la experiencia original, sus reminiscencias de la revolución para que toda la dotación fuera partícipe de una memoria emancipatoria esperanzadora. Así, una doble memoria de resistencia esclava pervivía en la zona, una local, la de la larga lucha de los esclavos de las minas del Cobre por su emancipación y la de los innumerables palenques que por décadas poblaron el área, y

28 Sobre la persistencia de la trata francesa, pese a las presiones inglesas y las disposiciones del gobierno para erradicarla véase: Daguet, 11/ 41 (París, 1971): 14-58. De acuerdo a Herbert Klein, los armadores de barcos de Nantes continuaron traficando con esclavos durante las primeras décadas del XIX y eran los únicos europeos aun activos en el comercio después de 1808. Klein, 2010: 203. Portuondo, 1996: 130-131.

29 Franco, 4 (La Habana, 1990): 2-3.

30 Departamento Oriental, partido rural de Brazo del Cauto. Estado que manifiesta los lugares, aldeas y fincas que en el contiene, ANC, Gobierno General, leg. 490, núm. 25134. 
otra la de Haití: la única insurrección de esclavos victoriosa del mundo Atlántico.

La literatura, en especial las narraciones de viajeros, abunda en idílicas descripciones del mundo cerrado de los cafetales de franceses, con casas de reminiscencias de chalets europeos en hermosísimos parajes de montañas, habitadas por propietarios ilustrados que tocaban piano y leían a Voltaire, y dotaciones felices y fieles, trabajando con obediencia en medio del aislamiento en la espesura de las serranías. Pero no sólo los documentos sino también los remanentes físicos de los cafetales desmienten la falacia. Aunque, a diferencia de las plantaciones azucareras de occidente, la zona no fue escenario de grandes sublevaciones esclavas, el cabildo de Santiago y los hacendados locales se vieron obligados a batallar constantemente contra un cimarronaje endémico que hacía una guerra sorda y persistente a la institución misma de la esclavitud. Y en varias de las ruinas que se conservan hasta hoy es frecuente encontrar cepos de castigo, grilletes y cadenas empotrados que testimonian de la violencia física que se ejercía contra los esclavos para obligarlos a trabajar ${ }^{31}$.

No obstante la existencia de esta múltiple memoria colectiva, local y trasnacional, de insurgencia esclava en el área y de la proximidad con ciudades como El Cobre y Santiago de Cuba, con grandes poblaciones de personas negras, muchas de ellas libres por varias generaciones, durante décadas el experimento de reimplantar en las serranías de Cobre la economía de la plantación esclavista que la revolución de Haití había hecho colapsar pareció ser exitoso. Salvo episodios aislados de desobediencia o cimarronaje ocasional, hasta el momento no he encontrado evidencias de que los cafetales de los Despaigne fueran escenario de sublevaciones esclavas de envergadura durante la primera mitad del siglo XIX. Hacia 1847, fecha de la muerte de Juan Despaigne, la familia poseía varias plantaciones en las serranías del Cobre, que, pese a sus hermosos nombres (La Lisse, Esmeralda, El Diamante o El Edén) prosperaban con el sudor y la sangre de más de 200 esclavos. El matrimonio de una hija de Pierre Despaigne con Thomas Brooks, un inglés asentado en Santiago después de hacer fortuna en Jamaica, aportaría una significativa inyección de capital al negocio familiar. La casa de comercio de Brooks, con vínculos en Nueva York, Londres, Nueva Orleáns y Kingston, facilitaría la comercialización del café y, seguramente, también la importación de la mano de obra esclava.

Es posible que al final de su vida, Juan y Pedro Despaigne pensaran que la prosperidad alcanzada y la aparente estabilidad política que reinaba en Cuba, pondría a cubierto para siempre a su descendencia de sufrir los efectos de la

31 Piron, 1995; Rosemond de Beauvallon, 2002; Bacardí Moreau, 1914. 
violencia de la guerra y la ruina. Pese a la decadencia progresiva del mercado cafetalero y a la escasez de mano de obra esclava debido al cese de la trata ilegal, a la altura de 1866 los descendientes de Pedro y Juan Despaigne poseían, repartidos en varios cafetales colindantes, un total de 664 esclavos cuyo valor se aproximaba al medio millón de pesos, una cantidad respetable en precios de la época ${ }^{32}$.

\section{LAS IDENTIDADES DE LOS ESCLAVOS}

Curiosamente, es la muerte de los amos franceses, hacia la mitad del siglo XIX, la que arroja luz sobre las vidas de los esclavos, que hasta ese punto de mi reconstrucción histórica habían permanecido en la sombra. Son justamente los listados incluidos en los avalúos de los testamentos donde la condición enajenada de las «personas con precio» ${ }^{33}$ aparece expresada de manera más obvia, al ser enumerados junto a las juntas de bueyes, las arrias de mulas y los aperos agrícolas, como una propiedad más de sus dueños, los que nos permiten conocer mejor la identidad de los esclavos.

Los testamentos de Juan Despaigne y su esposa en 1849, el de su hijo Juan José Leoncio, en 1858, y el de Rosa, la hija mayor de Pedro Despaigne, en $1865^{34}$, son una fuente invaluable de información sobre los esclavos: al listar sus nombres de pila, las habilidades especiales o los padecimientos, las edades y el sexo y las etnias, permiten esbozar, si bien muy pobremente, los rasgos individuales de los seres humanos sometidos a la esclavitud en los varios cafetales que la familia llegó a poseer. A su vez, las descripciones de los inmuebles que incluyen las casas de viviendas de los dueños y los secaderos y almacenes, así como las casas de esclavos, conucos y enfermerías, proporcionan elementos para poder imaginar los espacios donde transcurría la vida de cada día de la plantación.

Por los testamentos de la familia conocemos también que hacia la segunda mitad del siglo la proporción de africanos había ido disminuyendo en las plan-

32 Padrón de fincas rústicas de El Cobre, ANC, Gobierno General, legajo 265, núm. 19521.

33 Estoy usando la expresión acuñada por Walter Johnson en su excelente texto sobre el mercado de esclavos en Nueva Orleáns. Johnson, 1999.

34 Testamentaria de Juan Despaigne y su consorte Luisa Chalmette. ANC, Audiencia de Santiago de Cuba, legajo 171, núm.3089. Testamentaria de Juan José Leoncio Despaigne, consorte que fue de Isabel Dutocq. ANC, Audiencia de Santiago de Cuba, legajo 114, núm. 2253. Testamentaria de Rosa Despaigne y Ducongé, ANC, Audiencia de Santiago de Cuba, legajo 98, núm. 2050. 
taciones (para la década de 1860 habían nacido en África cerca de un tercio de los esclavos, los de mayor edad en la mayor parte de los casos). Así, para esta fecha las dotaciones estaban compuestas en buena parte por esclavos criollos, hijos y nietos de la primera generación de los esclavos congos e igbos o ibibios que desbrozaron el monte, construyeron las edificaciones y plantaron los primeros cafetos en Hongolosongo. Probablemente la existencia, constatable también en los testamentos, de un balance proporcional de ambos sexos entre los esclavos estimulaba la reproducción interna. Si bien los recién nacidos eran bautizados (frecuentemente de forma colectiva) en la cercana parroquia de Santiago del Prado en el Cobre, hecho que posibilita reconstruir los vínculos matrilineales (no se consignaba el nombre del padre) y de padrinazgo (que persisten mucho mas allá de la emancipación), en los libros que se conservan en la Parroquia no existen apenas asentamientos de matrimonios, lo cual no sólo pone en entredicho el pretendido catolicismo de los dueños franceses, sino que dificulta la reconstrucción de la estructura familiar entre los esclavos.

La manumisión parece haber sido extremadamente infrecuente, a juzgar por la ausencia en los registros notariales donde la familia solía asentar sus asuntos legales, del otorgamiento de cartas de libertad; hecho constatado además por la casi inexistencia de personas negras libres con el apellido Despaigne registradas en los padrones de Santiago de Cuba o en el cercano poblado del Cobre. No es hasta 1867 que, muy aisladamente, los propietarios franceses comienzan a conceder la libertad a algunos de sus esclavos.

En 1849, cuando dos años después de la muerte de Juan Despaigne sus herederos hacen un avalúo de las propiedades, María Luisa era una mujer africana de 32 años. Fue inscrita por sus amos como de nación «brichi» (o briche), lo que nos permite suponer que no era una esclava corriente. Entre los igbo del delta del río Níger, el término mbreechi era usado para designar un tipo de marcas, unas cicatrices especiales en la frente, que eran justamente un signo de distinción, una marca que indicaba un origen noble y una posición respetable dentro de la comunidad. Sólo podemos elucubrar acerca de qué infelices circunstancias arrastraron a esta mujer de cuna noble en África al otro lado del Atlántico, para terminar, rebautizada con un nombre occidental y esclavizada en un cafetal en el este de Cuba. Pero al menos es bastante probable haya sido honrada con el respeto de sus compañeros de infortunio, muchos de ellos también igbos de origen. O incluso quizás mereció también cierto reconocimiento de sus amos. En 1858 María Luisa era la lavandera del cafetal Isabelita, propiedad de la viuda y los hijos de Juan Leoncio Despaigne, uno de los hijos de Juan, muerto prematuramente en 1858. Aunque desempeñaba un oficio manual, era la única mujer en la plantación con oficio, y eso quizás le concedió un cierto status privilegiado que hizo posible su manumisión. En 1858, Rosi- 
llette, su hija de 12 años tasada en 700 pesos en el mismo testamento, era también una esclava del Isabelita. Uno puede imaginarse la cantidad de ropa sucia que María Luisa tuvo que lavar para reunir el dinero, no sólo para su manumisión sino también para comprar a su hija. En 1867 Luis Eugenio Despaigne, como apoderado de sus hermanos, concede un certificado de libertad a Rosillette, a cambio de 1.400 escudos que María Luisa les entregó al contado ${ }^{35}$.

Silvano, uno de los 82 esclavos que en la hipoteca del cafetal Estrella habían sido considerados en tanto propiedades «como unidos al suelo e inmuebles a causa de su destino», logra en 1867, a sus 40 años, librarse de esa condición de objeto y convertirse en un hombre libre. Apenas unos meses después Silvano compra a Henriette (o Enriqueta), su compañera de dotación de toda la vida y también su pareja, y a la pequeña hija de ambos, una niña de 15 meses llamada Margarita. Nacidos esclavos, Silvano y Enriqueta habían pasado casi cuatro décadas trabajando para los Despaigne. Considerados como propiedades habían sido objeto de una hipoteca para pagar una deuda contraída en París, del otro lado del Atlántico. Pero finalmente en 1867 ambos eran poseedores de un papel legal que consignaba, en blanco y negro, que sus antiguos dueños se desapoderaban «del derecho de posesión, propiedad y señorío». A partir de ese momento podrían «gozar de la libertad con todas las honras, gracias, mercedes y preeminencias que los libres de nacimiento pueden gozar», es decir «estar y transitar por donde quisieran», «tratar y contratar libremente» y «disponer a voluntad de sus bienes presentes y futuros». En pocas palabras, pagando por su libertad, habían pasado de ser «personas con precios» a personas con derechos ${ }^{36}$.

35 Testamentaria de Juan Despaigne y su consorte Luisa Chalmette, ANC, Audiencia de Santiago de Cuba, legajo 171, núm. 3089. AHPSC, Protocolos, año 1867, legajo 117, folio 398-399. Olaudah Equiano, un ex esclavo de origen igbo, autor de una autobiografía que se convirtió en un bestseller en el tiempo de su publicación original (1789) y es hoy día una de las más conocidas narrativas esclavas, testimonia acerca del especial estatus del «Embrenche», unas cicatrices especiales que eran una suerte de «mark of grandeur» entre la gente de su pueblo. Equiano, 2005. Véase la entrada «Equiano, Olaudah (1745-1797)», Falola y Warnock (eds.), 2007: 159-160. Sobre los igbos esclavizados en Norteamerica véase Chambers, 2005, y especificamente sobre el «mbreechi» y su significación como marca de honor entre los igbos, 2005: 159-160. Agradezco las referencias sobre el origen del término briche (mbreechi) y las recomendaciones bibliográficas a Henry Louis Gates y Linda Heywood.

36 AHPSC, Protocolos, año 1866, legajo 116, folio 12. AHPSC, Protocolos, año 1867, legajo 117, folio 12. AHPSC, Protocolos, año 1867, legajo 117, folios 408-409. 


\section{GUERRAS Y EMANCIPACIÓN}

Sin embargo, salvo casos aislados, no fue la manumisión el vehículo que proporcionó la libertad a los varios cientos de esclavos de los franceses. En 1868 el estallido de la primera guerra de independencia contra España echó abajo el espejismo de eterna bonanza, resquebrajando de manera permanente en la zona las bases de la prosperidad económica obtenida con el trabajo forzado de los esclavos. Pronto, al calor de los propios acontecimientos en la metrópoli, cuando el Sexenio democrático potenció la difusión de los discursos del republicanismo, comenzaron a circular en la zona del Cobre volantes plenos de la resonancia de los lenguajes de la libertad y los derechos ciudadanos.

Los hacendados franceses del partido, la mayor parte de ellos, como los Despaigne, hijos y nietos de colonos de Saint-Domingue, probablemente conocían mejor que nadie el peligroso alcance de esas palabras. Muy tempranamente armaron una guerrilla privada, una suerte de cordón sanitario que pretendía proteger a sus propiedades para aislarlas del contagio revolucionario. No obstante, los esfuerzos fueron vanos. La guerrilla, compuesta de criollos de la zona, se pasó íntegra, con hombres y armas, al bando independentista y en pocos días las tropas mambisas asolaban la zona incendiando los cafetales y liberando a buena parte de los esclavos, muchos de los cuales se incorporaron como soldados al Ejército Libertador ${ }^{37}$.

Uno de ellos, Simón Despaigne, hijo de Amelia, una esclava africana, pronto despuntó como líder local de la insurrección en el Cobre, participando en la toma de la ciudad en noviembre de 1868, en lo que fue uno de los primeros eventos victoriosos del recién creado Ejército Libertador cubano ${ }^{38}$. Probablemente Despaigne fuera testigo presencial de una curiosa ceremonia, de las primeras que tuvieron lugar en el proceso de «invención de la tradición mambisa»: la de la entrada oficial de Carlos Manuel de Céspedes, que también se estrenaba como Presidente de la República en Armas, al poblado del Cobre. Reproduzco la crónica tal y como la narra el historiador español Antonio Pirala:

Se procedió al alistamiento de cuantos estaban libres de servicio, se llamó a todos los negros de la población, de las minas y de las fincas vecinas, para que se situasen en las afueras, recomendando a los capataces llevasen banderas cubanas, y que al llegar el caudillo, diesen todos vivas a la República, a Carlos Manuel y a la libertad; se mandaron a decorar las calles y a que se iluminaran, y en cuanto se supo la aproximación de Céspedes, salió a recibirle el gobernador con su numeroso per-

37 Pirala, 1895, I: 291-293.

38 Ibidem: 314-315. 
sonal, todos a caballo, le encontraron en Loma del puerto del Cobre, le saludaron al descender por la cuesta con algunos disparos de un cañón muy antiguo, conseguido en la Socapa, al que denominaron Libertador, y al pasar por las filas de soldados y negros, estos batieron las palmas, dieron vivas atronadores, agitando las banderolas y entonaron sus cantos en jerga francesa, criolla y africana, que iban repitiendo en coro, acompañándose con sus tumbas, marugas y otros instrumentos de origen africano $^{39}$.

Es de notar el singular coro con cantos «en jerga francesa, criolla y africana» y el acompañamiento de instrumentos africanos como tumbas y marugas, con los que, en lugar de las marchas de resonancias europeas (como el mismo Himno de Bayamo, con sus reminiscencias de La Marsellesa), hizo su entrada triunfal el «Padre de la Patria» independentista en la ciudad. En 1868 el ejército mambí (un término también presumiblemente africano) nacía como un cuerpo interracial donde buena parte de las tropas de fila estaban compuestas de ex esclavos que se estrenaban también como soldados. Y como ya se ha dicho, muchos de los esclavos de la zona, liberados por las huestes independentistas, eran africanos, o sus hijos o nietos, y hablaban creole en lugar de español ${ }^{40}$.

El mismo Simón Despaigne, a pesar de que ostentaba en la guerra el grado de sargento, en 1874 aún no hablaba castellano. Según narra Fernando Figueredo, en ocasión del asesinato por las tropas españolas de Carlos Manuel de Céspedes en San Lorenzo, el sargento Simón Despaigne, enviado a explorar la zona para tratar de encontrar rastros del ex presidente, regresó al tiempo para comunicar en creole, «único idioma que poseía», a la vez que mostraba una ropa negra desgarrada y ensangrentada: «El Presidente es muerto: he aquí lo único que de él he encontrado» ${ }^{41}$. Simón Despaigne permaneció en el campo de batalla los diez años que duró la primera guerra. De hecho, perteneció al grupo de soldados que acompañaron a Antonio Maceo en su renuncia (simbólica) a rendir las armas ante España en el incidente conocido por el nombre de «Los mangos de Baraguá» ${ }^{42}$.

39 Ibidem: 324.

40 Sobre el complejo tránsito de esclavo a soldado y a ciudadano en Cuba véase: Ferrer, 2006: 304-329.

41 Figueredo, 1902: 41.

42 «Con la más justa y merecida recomendación de sus servicios y aptitudes tengo el honor de elevar a ese centro las propuestas de ascenso», escribiría en marzo de 1878 Antonio Maceo a Vicente García. Entre esas propuestas estaba la de conceder el grado de subteniente al sargento Simón Despaigne, por sus destacados servicios en la guerra. Antonio Maceo a Vicente García, Baraguá, 17 de marzo de 1878. ANC, Donativos y Remisiones, legajo 475, núm. 10. Agradezco esta información a Jorge Felipe, que generosamente compartió este documento conmigo. 
En 1895, cuando un ejército notablemente interracial (se cree que al menos el $60 \%$ de los miembros del Ejército Libertador eran negros o mestizos) se movilizó nuevamente en contra del colonialismo español, el ex esclavo Simón Despaigne tomó las armas nuevamente. Esta vez también un grupo grande de sus antiguos compañeros de dotación y sus descendientes, entre ellos Justo Despaigne, el dueño de la proclama cuyo asesinato da comienzo a mi historia, lo acompañaron en la empresa patriótica ${ }^{43}$.

En las peculiares circunstancias de la guerra cubana, muy a menudo, hombres blancos y letrados servían bajo el mando de oficiales negros o mulatos, en una situación límite donde lo que contaba era el coraje y la experiencia militar y no la riqueza o cultura, o el color de la piel. El caso del mayor general Antonio Maceo no era ni con mucho un ejemplo único. Hacia el final de la guerra se calcula que cerca de un $40 \%$ de los cargos de base en el ejército mambí eran desempeñados por hombres «de color», entre los que se contaban el ya entonces comandante Simón Despaigne, o Alfredo Despaigne, que alcanzó, peleando junto a Maceo en la invasión a Occidente, el grado de teniente coronel; y también varios de los futuros líderes del Partido de los Independientes de Color, como Evaristo Estenoz o Pedro Ivonnet, con cargos de oficiales en el ejército ${ }^{44}$.

Pero no sólo los jefes que tenían el mando sino también los innumerables soldados negros de fila que servían a sus órdenes, experimentaron, muchos por primera vez en su vida, la satisfacción de ser tratados con respeto y decoro en los campos de Cuba Libre, cosas raramente vividas antes por hombres provenientes, como los Despaigne, del mundo paupérrimo y denigrante de la esclavitud.

Las 122 personas negras de apellido Despaigne que aparecen listadas en los registros del Ejército Libertador corrieron suertes diferentes ${ }^{45}$. Algunos,

43 Justo Despaigne había participado junto a su padre Juan Despaigne, siendo apenas un adolescente en 1879, en la Guerra Chiquita, una insurrección de poca duración que tuvo lugar en el Oriente de Cuba, después de la terminación de la primera guerra de independencia. Su nombre aparece registrado como soldado en el listado del regimiento Cuba, segunda compañía con el núm 584. Véase: Documentación del General Camilo Polavieja, Segunda Campaña de Cuba, Correspondencia cogida al titulado general Guillermo Moncada, Listas del regimiento de Cuba, AGI, Diversos 7, folio 5821. Agradezco a Ada Ferrer el haber compartido conmigo esta información. El expediente de licenciamiento del Ejército Libertador de Justo Despaigne, donde se recoge su actuación en la guerra de 1895, puede consultarse en el ANC, Ejército Libertador, Primer Cuerpo, legajo 2, núm. 44.

44 Sobre el carácter interracial del ejército libertador y las luchas por la inclusión en la ciudadanía de los veteranos negros véase: Ferrer, 1999; Helg, 1995; Scott, 2 (Barcelona, 1999): 89-108; Scott, 2006.

45 Los registros de los 122 soldados y oficiales negros o mestizos de apellido Despaigne en el Ejército Libertador pueden consultarse en Roloff, 1901, o de manera digital, Base de Da- 
como Cecilio y Juan Bautista Despaigne, ambos veteranos de la guerra anterior, perdieron la vida en el campo de batalla. De Juan Bautista sólo he podido recuperar su nombre, inscrito en el registro de defunciones del Ejército, pero sabemos que Cecilio había peleado 9 años y seis meses en la primera guerra de independencia bajo las órdenes de Flor Crombet y tres meses en la Guerra Chiquita. En la campaña del 95 se incorporó bajo el mando del coronel Victoriano Garzón y después pasó a la escolta del general Cebreco, asistiendo a los combates de Sao del Indio, Arroyo Hondo, Jobito y otras acciones militares. Según sus compañeros armas, que como testigos acreditaron en 1904 su fallecimiento, Cecilio murió de herida de bala el 15 de junio de 1897 en el combate de Guáimaro, en Camaguey ${ }^{46}$. Otros, como Luciano y Simón Despaigne (no he podido constatar que tuviese alguna relación con el comandante, quizás fue un ahijado), nietos de esclavos africanos, fueron hechos prisioneros y enviados, en una especie de retorno simbólico a la tierra de sus ancestros, a cumplir penas de cadena perpetua a los presidios españoles de África. Luciano, que había sido apresado por las tropas españolas después de ser herido en combate en abril de 1896, fue liberado a la terminación de la guerra y alcanzó a regresar a Cuba a mediados de 1898. Simón tuvo peor suerte: con sólo 33 años murió de tuberculosis a inicios de 1899 recluido en la fortaleza del Hacho, en Ceuta ${ }^{47}$.

tos del Ejército Libertador de Cuba. Agradezco a Ed Elizondo, webmaster del sitio cubagenweb.org y al grupo de voluntarios que hicieron posible la transcripción de las cerca de 70.000 entradas del Índice alfabético del Ejército publicado por Roloff por hacer más accesible esta valiosa fuente.

46 Sobre la actuación en la guerra de 1895 de Cecilio Despaigne véase Hojas de servicios de diferentes miembros del Ejército Libertador, 6 de enero-6 de junio de 1896, ANC, Fondo Máximo Gómez, expediente 2643, legajo 19. Los detalles de su muerte aparecen en la declaratoria de herederos seguida por Simona Despaigne, su hermana natural, ambos eran hijos de Dolores y habían nacido esclavos en El Cobre. Véase Declaratoria de Herederos de Cecilio Despaigne, año 1904, AHPSC, Juzgado de Primera Instancia de Santiago de Cuba, expediente 1, legajo 75. Sobre los Despaigne caídos en campaña en la guerra de 1895 véase Roloff, 1901: 63 o la base de datos Defunciones del Ejército Libertador de Cuba.

47 El expediente de licenciamiento del Ejército Libertador de Luciano Despaigne, donde se resume su actuación en la guerra y su detención en Ceuta, puede consultarse en ANC, Fondo Ejército Libertador, Primer Cuerpo, legajo 16, núm. 144. La causa por rebelión a la que fue sometido (a sus 19 años) por un consejo de guerra y su hoja penal como prisionero en la fortaleza de la Cabaña en La Habana, antes de ser enviado al presidio de Ceuta a cumplir pena de reclusión perpetua, pueden consultarse en Cuaderno por rebelión contra Luciano Despaigne, 11 de octubre de 1896, ANC, fondo Asuntos Políticos, legajo 90, núm. 18. Sobre la defunción en Ceuta de Simón Despaigne, Base de datos Censo de Defunciones en Ceuta. 
Cuando en 1900 los Despaigne residentes en el Cobre votaron por primera vez, varios de ellos lo hicieron en los mismos predios donde antes habían sido esclavizados. Arruinada por las guerras, la familia blanca propietaria se había marchado a Europa, y la casa de vivienda abandonada de La Lisse hizo las veces de colegio electoral ${ }^{48}$. Sin embargo, pese al augurio prometedor con que comenzaba el nuevo siglo, en adelante el acceso a la ciudadanía sería dificultoso. De hecho, los veteranos negros tuvieron que batallar duramente por preservar incluso el tratamiento formal de ciudadano que los usos, orales y escritos, de la república en armas habían hecho prevalecer durante la guerra.

En 1900, en una carta pública al general Brooke, el gobernador militar norteamericano, un oficial negro, erigiéndose en vocero de su raza, afirmaba: «es tiempo ya de que desaparezcan para el bien del país y por respeto a la memoria de los mártires de nuestra libertad, los distintivos que para deprimir a nuestra raza y para dividir al pueblo cubano se usaban en los malos hábitos coloniales, cuyo vocabulario llamaba pardos o morenos a los libertos, mulatos o negros a los esclavos y criollos a los hijos del país de raza blanca. Para que en un no lejano tiempo podamos constituir una República ordenada, con un gobierno sólido y estable, capaz de favorecer y defender los derechos de todos, recurrimos a Ud., General, pidiéndole un decreto tendente a que se cumplan las leyes respecto a la desaparición de esos distintivos basados en la raza de los partes de la policía y demás documentos oficiales, y que en su lugar se emplee el único calificativo propio de un país libre: el honroso título de ciudadano» ${ }^{49}$.

En 1899, la exhumación de los restos del mismo Mayor general Antonio Maceo, caído en batalla tres años antes, después de 900 combates, 26 heridas de guerra y de haber perdido a su padre y a varios hermanos en los casi 30 años de luchas revolucionarias, se acompañó de un examen antropológico de sus restos. Las dimensiones de su cráneo y su osamenta se compararon con las de «parisienses» y «africanos» (los dos extremos en la escala de la «perfección» racial) y sólo después que una comisión «científica» dictaminó que si bien las medidas de sus huesos se correspondían con las de hombres de la raza negra, su cráneo no tenía nada que envidiar al de un «parisiense moderno», fue que Antonio Maceo fue declarado un «hombre superior» ${ }^{50}$.

48 Documentos sobre elecciones del Cobre. Junta electoral de Brazo del Cauto, año 1900, ANC, Secretaría de Gobernación, caja 237, núm. 14412.

49 Gutiérrez, 1900: 27.

50 Montalvo, De la Torre y Montané, 1900; Bronfman, 1998: 17-18. 
Así, la república cubana inaugurada en 1902, hija legítima de las guerras de independencia y bastardo de la intervención norteamericana, llevaba las marcas de su doble concepción: un código constitucional aprobado en 1901 garantizaba el sufragio universal (masculino) y otra serie de derechos liberales inclusivos; prerrogativas que las prácticas discriminatorias de una elite blanca notoriamente racista hacían lo posible por obstaculizar, tratando de poner límites a las demandas más radicales de los grupos subalternos alrededor de las políticas de inclusión en la nación y la ciudadanía.

En 1908, casi cien años después de la fundación del primer cafetal de los Despaigne, en la misma zona del Cauto aledaña al Cobre, vivían todavía, labrando la tierra como campesinos o trabajando de peones en las haciendas vecinas, varias decenas de personas descendientes de los cientos de esclavos que una vez tuvo la familia francesa ${ }^{51}$. Extremadamente pobres y analfabetos en su abrumadora mayoría, estos hombres percibían, no obstante, que habían ganado con sangre el derecho a tener derechos, en la república que habían ayudado a fundar con su masiva incorporación al Ejército Libertador. De este modo, cuando en 1908 Evaristo Estenoz y Pedro Ivonnet fundaron el Partido de los Independientes de Color, denunciando la preterición que los hombres de su raza sufrían, numerosos veteranos orientales como Simón Despaigne, Ricardo, Marcelino, Arcadio y otras 20 personas más, todas del mismo apellido, se sumaron prontamente, formando parte de las juntas locales del partido en el Cobre ${ }^{52}$.

\section{LA GUERRA DE 1912 Y EL FANTASMA DE HAITÍ}

En 1912, luego de que una enmienda al artículo 17 de la ley electoral aprobada por la Cámara de Representantes ilegalizó la existencia del Partido de los

51 Registro electoral, Municipio Cobre, provincial de Oriente, año 1908, ANC, Secretaría de Gobernación, legajo 261, expediente 14477. El documento que lista a los electores (hombres todos en cuanto el sufragio denominado «universal» era en realidad masculino) consignando los nombres y las direcciones pero también la edad, raza, profesión, estado civil y el grado de alfabetización, evidencia que decenas de personas de apellido Despaigne, negras y mulatas, analfabetas en su gran mayoría, habitaban labrando la tierra en los mismos predios donde más de tres décadas antes habían sido esclavizados.

52 Para la constitución de los comités locales del Partido de los Independientes de Color en 1910 en el Cobre véase: Previsión, 30 de enero, 5, 10 y 25 de marzo de 1910. Además del texto, ya todo un clásico, de Helg, 1995, para la historia del Partido de los Independientes de Color véase: Portuondo Linares, 2002; Castro Fernández, 2002; Meriño, 2006; Riquenes, 2007. 
Independientes de Color, sus líderes decidieron volver a las armas. La insurrección, que nunca pasó de ser un gesto simbólico de protesta (los alzados evadían sistemáticamente el combate), fue rápidamente etiquetada como «racista» y acusada de ser una "guerra de negros contra blancos» que ponía en peligro la estabilidad de la joven república. Simón Despaigne había nacido cerca de 1830 en el Cobre, esclavo de los Despaigne, y obtuvo su emancipación peleando en la primera guerra de independencia en 1868. A partir de esa fecha estuvo en todas las guerras de Cuba. En 1912, cuando se alzó nuevamente, tenía más de 80 años, aun era analfabeto y hablaba español con acento creole. De nada le valió haber estado con Carlos Manuel de Céspedes desde los mismos inicios de las campañas por la independencia, o haber acompañado a Antonio Maceo en un sinnúmero de combates donde fue herido en tres ocasiones, o poseer un certificado de veterano donde se consignaba literalmente que en tanto soldado de la Patria era «merecedor del respeto y la consideración de sus conciudadanos». Fue hecho prisionero y hacinado con otros cientos de «rebeldes» en la cárcel de Santiago de Cuba, acusados de «racistas» y sometidos a vejaciones y malos tratos.

Nuevamente la memoria del grand peur de la revolución de Haití resurgió con fuerza. El argumento de la amenaza de una «guerra de razas» que reprodujera en la isla «los horrores de Haití» se había esgrimido a lo largo del siglo XIX en cada ocasión en que personas negras, esclavas o libres intentaron hacer valer sus derechos a la libertad, a la igualdad o al acceso a la ciudadanía. Lo mismo un acto de cimarronaje, una sublevación de esclavos o que, años más tarde, los episodios de las insurrecciones independentistas, fueron interpretados como conatos de la reedición en la isla de Cuba de la subversión violenta del orden, racial y social, a los que se asociaba la memoria de la revolución en Haití. Las más de las veces, se trataba, sin duda, de cargos infundados. Sin embargo, en este caso, la asociación se veía reforzada por los apellidos de origen francohaitiano de algunos de los líderes nacionales del alzamiento, como Pedro Ivonnet, Gregorio Surín y Eugenio Lacoste (nietos todos de colonos franceses de Saint-Domingue), y también de muchos de los movilizados negros en la zona del oriente de la isla, que al igual que los 34 Despaigne que se incorporaron al alzamiento, eran descendientes de los esclavos de los plantadores franceses ${ }^{53}$.

53 Causa seguida por el delito de rebelión contra Evaristo Estenoz, Pedro Ivonet y otros, relacionado con el movimiento revolucionario denominado "Guerra de la raza», ANC, Audiencia de Santiago de Cuba, legajo 51, núm 6, pieza 94, Relación de los individuos rebeldes que se acogieron a la legalidad con motivo de los bandos publicados en 6 y 11 de junio de 1912, folios 1861-1864. 
Esta vez el alzamiento sí parecía confirmar la sospecha paranoica del racismo blanco, de un fantasma de Haití, que regresa inexorablemente para ajustar las cuentas del pecado irredimible de la esclavitud. De hecho, únicamente el temor obsesivo permite explicar no sólo la emergencia de un racismo tan descarnado, sino también la violencia misma de la represión: en menos de dos meses, durante el verano de 1912, la suspensión de las garantías constitucionales facilitó el asesinato impune de cerca de 3.000 personas negras, entre ellos los líderes nacionales del partido, cuyos cadáveres fueron expuestos y mostrados en fotografías vejatorias, en las primeras planas de los periódicos, tratados como los más vulgares delincuentes comunes.

Sin embargo, más allá del terror enfermizo de la paranoia blanca, mi reconstrucción microhistórica de la cadena de acontecimientos que enlaza la huida de la familia Despaigne de Saint-Domingue en 1803, con el asesinato del ex esclavo y veterano negro Justo Despaigne en 1912, parece confirmar la existencia de una memoria viva, local en la zona de Oriente, del legado antiesclavista y antirracista de la revolución de Haití. En mi interpretación, esa memoria mayormente oral (la inmensa mayoría de los esclavos y sus descendientes eran analfabetos), transmitida de padres a hijos, más tarde hizo filas junto a la ideología antiesclavista del republicanismo blanco de las elites, y sirvió de impulso a la potente movilización que culminó en el este de Cuba con la masiva incorporación de la gente libre de color, junto a los esclavos y sus descendientes, entre ellos numerosos antiguos esclavos de la familia Despaigne, primero a las guerras de independencia contra España, y ya en el siglo XX, a la causa del Partido de los Independientes de Color.

\section{BIBLIOGRAFÍA}

Appiah, Kwame Anthony y Gates, Henry Louis (eds.), Africana: the Encyclopedia of the African and African American Experience, Oxford, Oxford University Press, 2005 (2. ${ }^{\mathrm{a}}$ ed.).

Bacardí Moreau, Emilio, Via Crucis, Barcelona, Imprenta de la viuda de Luis Tasso, 1914.

Barcia, Manuel, «Les "Epines de la Truite"», Nuevo Mundo Mundos Nuevos, 2008, http://nuevomundo.revues.org/33062, consultado el 16 diciembre 2010.

Base de Datos del Ejército Libertador de Cuba, http://www.cubagenweb.org.

Bronfman, Alejandra, «Reading Maceo's Scull (Or the Paradoxes of Race in Cuba)», Program in Latin American Studies. Boletín, Princenton University, fall 1998: 17-18. 
Callejas, José María, Historia de Santiago de Cuba, La Habana, Imprenta La Universal, 1911.

Castro Fernández, Silvio, La masacre de los Independientes de Color en 1912, La Habana, Ciencias Sociales, 2002.

Censo de Defunciones en Ceuta, http://www.cubagenweb.org, consultado el 15 de diciembre del 2010.

Chambers, Douglas B., Murder at Montpelier: Igbo Africans in Virginia, Jackson, University Press of Mississippi, 2005.

Cruz Ríos, Laura, Flujos migratorios franceses a Santiago de Cuba, Santiago de Cuba, Editorial Oriente, 2006.

Daguet Serge, «L'abolition de la traite des Noirs en France de 1814 à 1831», Cahiers d'études africaines, Vol. 11/ 41 (París, 1971): 14-58.

De la Rosa Corzo, Gabino, Los Palenques del Oriente de Cuba. Resistencia y acoso, La Habana, Editorial Academia, 1991.

Defunciones del Ejército Libertador de Cuba, http://www.cubagenweb.org, consultado el 15 de diciembre del 2010.

Deschênes, Ronald, «Du sillage de la mer aux sillons d'une habitation; Jacques Kanon, colon à Jérémie», Genese. Journal genealogique et historique, Association de Généalogie d'Haïti, http://www.agh.qc.ca/articles/?id=72, consultado el 16 diciembre del 2010a.

Deschênes, Ronald, «Trois marins français à Québec (1758-1759)», http://membres.multimani, consultado el 16 diciembre del 2010b.

Díaz, María Elena, The Virgin, the King and the Royal Slaves of El Cobre. Negotiating Freedom in Colonial Cuba, 1670-1780, Stanford, California, Stanford University Press, 2000.

Dubois, Laurent, Avengers of the New World. The Story of the Haitian Revolution, Cambridge Mass., Harvard University Press, 2004.

Eltis, David y Richardson, David, "A new assessment of the Transatlantic Slave Trade», David Eltis y David Richardson (eds.), Extending the Frontiers: Essays on the New Transatlantic Slave Trade Database, New Haven \& Londres, Yale University Press, 2008.

Engerman, Stanley L., Slavery, Emancipation and Freedom: Comparative Perspectives, Baton Rouge, Louisiana State University Press, 2007.

Equiano, Olaudah, The Interesting Narrative of the Life of Olaudah Equiano, Or Gustavus Vassa, The African, 2005, consultado digitalmente en The Project Gutenberg Ebook (EBook \#15399).

Falola, Toyin y Warnock, Amanda (eds.), Encyclopedia of Middle Passage, Westport, Connecticut, Londres, Greenwood Press, 2007. 
Ferrer, Ada, Insurgent Cuba. Race, Nation, and Revolution, 1868-1898, Chapel Hill y Londres, The University of North Carolina Press, 1999.

Ferrer, Ada, «La société esclavagiste cubaine et la révolution haïtienne», Annales, 2 (París, marzo-abril, 2003): 335-336.

Ferrer, Ada, «Noticias de Haití en Cuba», Revista de Indias, LXIII/ 229 (Madrid, 2003): 675-694.

Ferrer, Ada, «Armed Slaves and Anticolonial Insurgency in Late Nineteenth-Century Cuba», Christopher Leslie Brown y Philip D. Morgan (eds.), Arming Slaves: From Classical Times to the Modern Age, New Haven \& Londres, Yale University Press, 2006: 304-329.

Ferrer, Ada, «The Archive and the Atlantic's Haitian Revolution», Doris Lorraine Garraway (ed.), Tree of Liberty: Atlantic Legacies of the Haitian Revolution, Charlottesville, University of Virginia Press, 2008.

Ferrer, Ada, «Speaking of Haiti: Slavery and Freedom in Cuban Slave Testimony», David Geggus y Norman Fiering (eds.), The World of the Haitian Revolution, Bloomington, University of Indiana Press, 2009.

Fick, Carolyn E., The Making of Haiti: The Saint Domingue Revolution from Below, Knoxville, The University of Tennessee Press, 1990.

Figueredo, Fernando, La Revolución de Yara, 1868-1878, La Habana, M. Pulido y Cía impresores, 1902.

Fischer, Sibylle, Modernity Disavowed. Haiti and the Cultures of Slavery in the Age of Revolution, Durham, Duke University Press, 2004.

Franco, José Luciano, «Africanos y sus descendientes criollos en las luchas libertadoras: 1533-1895», Boletín de Archivo Nacional, 4 (La Habana, 1990): 2-3.

Geggus, David, «The French Slave Trade: An Overview», The William and Mary Quarterly, 3ra Ser., Vol. 58/ 1 (Williamsburg, Virginia 2001): 19-138.

Geggus, David, «Saint-Domingue on the eve of the Haitian Revolution», Davis Patrick Geggus y Norman Fiering (eds.), The World of Haitian Revolution, Bloomington, Indiana University Press, 2009.

González-Ripoll, María Dolores, Naranjo, Consuelo, Ferrer, Ada, García, Gloria y Opatrný, Josef, El rumor de Haití en Cuba: temor, raza y rebeldía, 1789-1844, Madrid, CSIC, 2004.

Grandío Moraguez, Oscar, «The African Origins of Slaves Arriving in Cuba, 1789-1865», David Eltis y David Richardson Extending the Frontiers: Essays on the New Transatlantic Slave Trade Database, New Haven \& Londres, Yale University Press, 2008.

Gutiérrez, José Margarito, Páginas para la historia, La Habana, Imprenta la Prueba, 1900. 
Helg, Aline, Our Rightful Share. The Afro-Cuban Struggle for Equality, 1886-1912, Chapel Hill \& Londres, The University of North Carolina Press, 1995.

Johnson, Walter, Soul by Soul. Life Inside the Antebellum Slave Market, Harvard, Harvard University Press, 1999.

Klein, Herbert S., The Atlantic Slave Trade, Nueva York, Cambridge University Press, 2010.

Knight, Franklin W., «The Haitian Revolution», The American Historical Review, Vol. 105/ 1 (Washington, 2000): 103-115.

Lachance, Paul F., «The 1809 Immigration of Saint-Domingue Refugees to New Orleans: Reception, Integration and Impact», Louisiana History: The Journal of the Louisiana Historical Association, Vol. 29/ 2 (Lafayette, LA,1988): 109-141.

Manuel, Keith Anthony, «Slavery, Coffee, and Family in a Frontier Society: Jérémie and its Hinterland, 1780-1789», MA Thesis (Tesis de Maestría), Gainesville, University of Florida, 2005.

McCusker, John J. (ed.), History of World Trade since 1450, Farmington Hills, Thomson-Gale, 2006.

Meriño Fuentes, María de los Ángeles, Una vuelta necesaria a mayo de 1912. El alzamiento de los Independientes de Color, La Habana, Ciencias Sociales, 2006.

Mintz, Sidney W., Sweetness and Power. The Place of Sugar in Modern History, Harmondsworth, Penguin, 1985.

Montalvo, J. R., de la Torre, C. y Montané, L., El cráneo de Antonio Maceo (Estudio antropológico), La Habana, Imprenta Militar, 1900.

Orozco Melgar, María Elena, Presencia francesa e identidad urbana en Santiago de Cuba, Santiago de Cuba, Ediciones Santiago, 2002.

Orozco Melgar, María Elena, «Louis Francois Delmés: el cartógrafo francés de Santiago de Cuba», Anales del Museo de América, 14 (Madrid, 2006): 255-284.

Pérez de la Riva, Juan, «La Implantación francesa en la cuenca superior del Cauto», El Barracón y otros ensayos, La Habana, Ciencias Sociales, 1975.

Piqueras, José A., «Coacción, voluntariedad y libertad en el trabajo colonial: una historia atlántica», José A. Piqueras (ed.) Trabajo libre y coactivo en sociedades de plantación, Madrid, Siglo XXI: 3-50.

Pirala y Criado, Antonio, Anales de la guerra de Cuba, T.I, Madrid, F. Gonzailez Rojas, 1895.

Piron, Hipolytte, La Isla de Cuba, Santiago de Cuba, Editorial Oriente, 1995.

Portuondo Linares, Serafín, Los Independientes de Color, La Habana, Editorial Caminos, 2002.

Portuondo, Olga, Santiago de Cuba, desde su fundación hasta la Guerra de los Diez Años, Santiago de Cuba, Editorial Oriente, 1996. 
Portuondo, Olga, «La inmigración negra de Saint-Domingue en la jurisdicción de Cuba», Entre esclavos y Libres de Cuba Colonial, Santiago de Cuba, Editorial Oriente, 2003.

Price, Richard (comp.), Sociedades cimarronas. Comunidades esclavas rebeldes en las Américas, México, Siglo XXI, 1981.

Putnam, Lara, «To Study the Fragments/Whole: Microhistory and the Atlantic World», Journal of Social History, Vol. 39/ 3 (Fairfax, VA, 2006): 615-630.

Riquenes Herrera, Ricardo Rey, Guantánamo en el vórtice de los Independientes de Color, Guantánamo, Editorial El Mar y La Montaña, 2007.

Roloff y Mialofsky, Carlos, Índice Alfabético y defunciones del Ejército Libertador de Cuba, La Habana, Imprenta de Rambla y Bouza, 1901.

Rosemond de Beauvallon, J. B., La Isla de Cuba, Santiago de Cuba, Editorial Oriente, 2002.

Saugera, Eric, Bordeaux, port négrier, XVIIe-XIXe siècles, París, Karthala, 1995.

Scott, Julius, The Common Wind. Currents of Afro-American Communication in the Era of the Haitian Revolution, Tesis doctoral, Duke University, 1986.

Scott, Rebecca J., «Reclamando la mula de Gregoria Quesada. El significado de la libertad en los valles de Arimao y del Caunao, Cienfuegos, Cuba», Islas e Imperios, 2 (Barcelona, 1999): 89-108.

Scott, Rebecca, «Small-Scale Dynamics of Large-Scale Processes», Forum: «Crossing Slavery's Boundaries», American Historical Review, 105 (Washington, 2000): 472-479.

Scott, Rebecca J., Grados de Libertad, La Habana, Ciencias Sociales, 2006.

Scott, Rebecca J., «Reinventar la esclavitud, garantizar la libertad. De Saint-Domingue a Santiago a Nueva Orleáns, 1903-1809», Caminos, 52 (La Habana, 2009): 2-14.

Scott, Rebecca J. y Hébrard, Jean M., «Rosalie of the Poulard Nation: Freedom, Law, and Dignity in the Age of the Haitian Revolution», John D. Garrigus y Christopher Morris (eds.), Assumed Identities. The Meanings of Race in the Atlantic World, Arlington, University of Texas at Arlington by Texas A\&M Press, 2010: 116-143.

Smith, Jeremy, Europe and the Americas. State Formation, Capitalism and Civilizations in Atlantic Modernity, Leiden-Boston, Brill, 2006.

Texera, Agustín de la, «Santiago de Cuba a principio del s. XIX», Revista del Caribe, 13 (Santiago de Cuba, 1989): 90-96.

Transatlantic Slave Trade Database, http: //www.slavevoyages.org, consultado el 20 de diciembre del 2010.

Fecha de recepción: 16-3-2010

Fecha de aceptación: 30-6-2010 


\section{THE DESPAIGNES IN SAINT-DOMINGUE AND CUBA: A MICRO-HISTORICAL NARRATIVE OF AN ATLANTIC EXPERIENCE}

A family of French planters in Jérémie, in southern Saint-Domingue, whose world falls apart due to the revolution in Haiti, recreates the economy (material and moral) of the coffee plantation in the El Cobre Mountains, in Santiago de Cuba. Half a century later, the breakout of the Cuban wars of independence from Spain emancipated the numerous slaves from the plantation. Their citizen status, in the Cuban Republic of the 20th century, was put to the test as the 1912 uprising of the Independent Party of Color traumatically brought back the memory of Haiti to Cuba.

Key words: Haiti, Cuba, slavery, emancipation, race. 